\title{
Retinoblastoma in Asia
}

\author{
Mukesh Jain ${ }^{1} \cdot$ Duangnate Rojanaporn $^{2} \cdot$ Bhavna Chawla $^{3} \cdot$ Gangadhar Sundar $^{4} \cdot$ Lingam Gopal $^{4} \cdot$ Vikas Khetan $^{1}$
}

Received: 18 September 2018 / Revised: 23 September 2018 / Accepted: 4 October 2018 / Published online: 1 November 2018

(c) The Royal College of Ophthalmologists 2018

\begin{abstract}
Asia-Pacific region bears a significant global burden of retinoblastoma (RB), therefore understanding RB in Asia-Pacific region is important. Based on the year 2013 population estimates, 43\% (3452 of 8099 children) of the global burden of RB lives in 6 countries of Asia-Pacific region: 1486 children in India, 1103 children in China, 277 children in Indonesia, 260 children in Pakistan, 184 children in Bangladesh, 142 children in Philippines. There exists a wide disparity, technological and socio-economical, within countries in this region resulting in a varied pattern of clinical presentation and survival varies. Challenges in developing nations are not just technological, but also social. Opportunities emerge for research to study and understand the socio-economical aspects of the disease to develop interventions that are relevant culturally and feasible economically. Possible steps include disease education and counselling, universal screening, highly subsidized/free of cost treatment for low socioeconomic strata, raising funds through the government and non-governmental organizations, sensitization and training of man-power in screening, diagnosis and treatment, and developing new specialized centers with tele-ophthalmology services.
\end{abstract}

\section{Introduction}

Retinoblastoma (RB) is the most common primary intraocular malignancy of childhood worldwide with a uniform incidence rate across population at 1 in 15000-20000 live birth corresponding to about 9000 new cases every year [1,2]. In the last 100 years significant progress has been made in the diagnosis and management of RB keeping the principles of Life, Globe \& Vision salvage in order of priority [3, 4].

Prognosis and survival depends on early diagnosis and appropriate treatment [5]. With more than $90 \%$ of $\mathrm{RB}$ children living in under developed nations, it is troubling

Vikas Khetan

drvk@snmail.org

1 Shri Bhagwan Mahavir Vitreoretinal Services, Medical Research Foundation, Sankara Nethralaya, Chennai 600006 Tamil Nadu, India

2 Department of Ophthalmology, Ramathibodi Hospital, Mahidol University Faculty of Medicine, Bangkok, Thailand

3 Dr. Rajendra Prasad Centre for Ophthalmic Sciences, All India Institute of Medical Sciences, New Delhi, India

4 Retinoblastoma Service, Department of Ophthalmology, National University Hospital, National University of Singapore 119074, Singapore that these children die of a potentially curable tumor with high survival rates $[6,7]$. In developed countries, the goal of treatment has shifted from globe salvage to vision preservation [8-10]. However, preventing death is a major challenge in under developed nations where most children have advanced disease at presentation [11-14].

Obvious drastically different outcomes between developed and under-developed nations are troubling [7, 15]. Various factors in combinations, both technological and social, are responsible for poor outcomes seen in less privileged nations (Table 1) [16].

Together, 43\% (3452 of 8099 children) of the global burden of RB lives in these 6 countries: 1486 children in India, 1103 children in China, 277 children in Indonesia, 260 children in Pakistan, 184 children in Bangladesh, 142 children in Philippines [17]. Interestingly, owing to the explosive population growth in Asia-Pacific region, recently $\mathrm{RB}$ has outnumbered uveal melanoma to become the most common ocular malignancy globally [2]. With the current trend observed, the global burden is expected to increase by 100 cases a year.

Understanding RB in Asia-Pacific region is important [17]. However, scarce optimal quality scientific literature exists from most of these countries. Moreover, there exists a wide disparity, technological and socio-economical, within countries in this region resulting in a varied pattern of clinical presentation and survival varies. Opportunities 
Table 1 Various factors in combinations, both technological and social, are responsible for poor outcomes seen in less privileged nations

- Lack of awareness about RB in general population- delay in seeking medical attention

- Lack of National Screening Program

- Lack of training in screening, diagnosis and referral of RB: primary health care workers, pediatricians, gynecologist, primary physician, medical graduates

- Few treatment centers with trained personal specialized in treating RB

- Inadequate Infrastructures

- Accessibility

- Financial issues

- Socio-economic factors, extended family pressure, religious belief, gender bias

- Alternative indigenous system of treatment

- Poor compliance to treatment

- Lack of multi-disciplinary team in one roof

- Lack of proper counselling and support group

- Lack of prosthetic shell fitting clinic

- Lack of support from government and non-government NGO, telemedicine facility, National cancer registry.

emerge for research to study and understand the socioeconomical aspects of the disease to develop interventions that are relevant culturally and feasible economically.

\section{Retinoblastoma in India}

India carries the biggest burden of Retinoblastoma, both in Asia-Pacific region and globally, with an estimated 1500 new cases detected every year. We conducted a systemic PubMed search of all articles, published between 2008 and 2018, reporting the presentation, treatment and survival of $\mathrm{RB}$ in Indian children. Data from 4 large series constituting a total of $2697 \mathrm{RB}$ children were gathered and analyzed [18-21].

Table 2 shows the baseline characteristics of $2591 \mathrm{RB}$ children at presentation. "Familiar" cases constituted approximately $4-6.3 \%$ of the total case [18-21]. Kaliki et al. reported that the mean age at presentation for "familiar" cases was 24 months vs. 29 months in the overall group [19].

Although no sex predisposition have been noted for $\mathrm{RB}$ worldwide, a male preponderance was noted in all studies constituting approximately $60 \%$ of all cases [18]. Singh et al. reported that among children with advanced disease at presentation $87.2 \%$ were girls and $81.0 \%$ were boys
Table 2 Baseline characteristics of $2591 \mathrm{RB}$ children at presentation in India

\begin{tabular}{|c|c|c|c|}
\hline & $\begin{array}{l}\text { Chawla et al. } \\
{[18]}\end{array}$ & $\begin{array}{l}\text { Singh et al. } \\
{[20]^{*}}\end{array}$ & $\begin{array}{l}\text { Kaliki } \\
\text { et al. }[19]^{\#}\end{array}$ \\
\hline Time span of the study & 2009-2013 & 1998-2014 & $\begin{array}{l}2000- \\
2015\end{array}$ \\
\hline Total eyes/ children & 667 children & $618 / 467$ & $2074 / 1457$ \\
\hline Familiar cases $(\%)$ & 6.3 & 4 & 4 \\
\hline Male/Female (\%) & $61.2 / 38.8$ & $61.7 / 38.3^{\mathrm{a}}$ & $56 / 44$ \\
\hline Rural/ Urban (\%) & & $53.5 / 46.5^{\mathrm{b}}$ & \\
\hline Unilateral / bilateral (\%) & $67.6 / 32.4$ & $67.7 / 32.3$ & $57 / 43$ \\
\hline $\begin{array}{l}\text { Leucocoria presenting } \\
\text { symptom }(\%)\end{array}$ & 83 & 60.6 & 75 \\
\hline $\begin{array}{l}\text { Children with proptosis } \\
\text { at presentation }(\%)\end{array}$ & 17 & 4.4 & 6 \\
\hline $\begin{array}{l}\text { Mean age at presentation } \\
\text { - overall (months) }\end{array}$ & 29 & $\begin{array}{l}34.4 \\
+/-24.6\end{array}$ & 29 \\
\hline - Unilateral/Bilateral & $36 / 18$ & $36 / 30$ & $34 / 21$ \\
\hline - Male/Female & & & $29 / 28^{\mathrm{c}}$ \\
\hline $\begin{array}{l}\text { - Intra-ocular/Extra- } \\
\text { ocular }\end{array}$ & $24 / 37.5$ & & $27 / 44$ \\
\hline - Familiar cases & & & 24 \\
\hline $\begin{array}{l}\text { Delay in seeking medical } \\
\text { consultation (months) }\end{array}$ & 3 & $8.3+/-13.8$ & \\
\hline $\begin{array}{l}\text { Age }>5 \text { years at } \\
\text { presentation }(\%)\end{array}$ & 7.5 & 10.9 & 7 \\
\hline $\begin{array}{l}\text { Intra-ocular/ Extra-ocular } \\
\text { (Orbital) }(\%)\end{array}$ & $72.3 / 27.7$ & $64.5 / 35.5$ & $91 / 9^{c}$ \\
\hline \multicolumn{4}{|l|}{ Stage at presentation $(\%)$} \\
\hline$\bullet 0$ & & 64.5 & 45 \\
\hline - 1 & & & 45 \\
\hline$\cdot 2$ & & & 2 \\
\hline$\cdot 3$ & 23.3 & 33.8 & $6^{\mathrm{c}}$ \\
\hline - 4 & 4.3 & 1.7 & 3 \\
\hline \multicolumn{4}{|l|}{ Group at presentation (\%) } \\
\hline - A & & 12.2 & 6 \\
\hline - B & 15 & & 15 \\
\hline$\cdot \mathrm{C}$ & & & 7 \\
\hline$\cdot \mathrm{D}$ & 14 & $77.8^{\mathrm{d}}$ & $22^{\mathrm{c}}$ \\
\hline$\cdot \mathrm{E}$ & 64 & & 51 \\
\hline
\end{tabular}

${ }^{*}$ Clinical features at presentation were based on individual eyes

${ }^{\#}$ Grouping and staging at presentation was not based on worst eye

${ }^{\mathrm{a}} \mathrm{A}$ total of $87.2 \%$ of female had advanced disease at presentation as compared to $81.0 \%$ of male $(p=0.052)$

bIn all, $12.9 \%$ of the children were "below poverty line"

${ }^{\mathrm{c}}$ The mean age of presentation for female children, occurrence of extra-ocular disease, ICIoR Group D and IRSS Stage 3 gradually decreased over the 15 years study period $(p<0.05)$

${ }^{\mathrm{d}}$ In all, 234 of 301 patients in the intra-ocular group presented with advanced disease 
$(p=0.052)[20]$. Nearly $53.5 \%$ of the children were from rural areas and $13 \%$ children were from below poverty line (BPL) families in one series [20].

Leukocoria was the most common presenting symptom in approximately $61-83 \%$ of the cases [18-21]. Proptosis was seen in $2.8-17 \%$ of children at presentation [18-21].

The overall mean age of presentation was 29-34 months with $7-10.5 \%$ of children being older than 5 years at presentation [18-20]. Singh et al. and Chawla et al. reported a mean delay in presentation was 3 and 8.3 months, respectively [18-20]. One study found a statistically significant difference between intra-ocular and extra-ocular groups in the median lag period [18].

Children with unilateral RB constituted approximately $56-61.7 \%$ of the cases [18-21]. Children with unilateral $\mathrm{RB}$ presently late as compared to children with bilateral RB (34-36 vs. 18-30 months) [18-21]. Chawla et al., Singh et al. and Kaliki et al. reported 27.6\% (23.3\% Stage 3 $\& 4.35 \%$ Stage 4), $35.5 \%$ (33.8\% Stage $3 \& 1.7 \%$ Stage 4) and $9 \%(6 \%$ Stage $3 \& 3 \%$ Stage 4) children had extra-ocular RB at presentation [18-20]. Proptosis was the most common presenting symptom, although few neglected case presented with a fungating orbital with metastasis [18-20].

Among those with intra-ocular RB, advanced disease (Group D/E) was present in 73-78\% children [18-20].

Kaliki et al. performed a sub-group analysis found that the mean age of presentation for female child, occurrence of extra-ocular disease, ICIoR Group D and IRSS Stage 3 has gradually decrease over the 15 -year study period $(p<0.05)[19]$.

Table 3 below shows the treatment, globe salvage and survival rates of $2697 \mathrm{RB}$ children in India. 49.5 and 60.4\% of children in Chawla et al. and Shah et al. series underwent primary enucleation [18-21]. Kalaki et al. observed that in eyes undergoing primary enucleation high-risk characteristic on histo-pathological examination (HPE) was noted in 35 and $23 \%$ eyes in India and United States, respectively $(p=0.003)[22]$.

Chawla et al. reported an overall $28.2 \%$ globe salvage rate in eyes with intra-ocular RB eyes (Group A: 100\%; Group B: 94\%; Group C: 83\%; Group D: 54\%; Group E: $0 \%$ ) [18]. Singh et al.reported 100, 100, 94.7, 17.4 and 0\% globe salvage rate in Group A, B, C, D and E, respectively [20]. Similarly, Shah et al. reported 100, 100, 100, 29.4 and $0 \%$ globe salvage rate in Group A, B, C, D and E, respectively [21].

Overall survival rates reported were $75.7-92 \%$ in the 4 studies with a mean/median follow-up of 21-44 months [18-21]. Chawla et al. reported the survival probability in the extraocular group was 60,43 and $35 \%$, respectively, at the end of 1 year, 2 years and 5 years, as compared with 93 , 85 and $78 \%$ in the intraocular group $(p<0.001)$ [18]. Shah
Table 3 Treatment, global salvage and survival rates of $2697 \mathrm{RB}$ children in India

\begin{tabular}{|c|c|c|c|c|}
\hline & $\begin{array}{l}\text { Chawla } \\
\text { et al. [18] }\end{array}$ & $\begin{array}{l}\text { Singh et al. } \\
{[20]^{*}}\end{array}$ & $\begin{array}{l}\text { Kaliki } \\
\text { et al. [19] }\end{array}$ & $\begin{array}{l}\text { Shah et } \\
\text { al. [21] }\end{array}$ \\
\hline Primary enucleation & 49.4 & - & - & 60.4 \\
\hline $\begin{array}{l}\text { HRC in specimens } \\
\text { of primary } \\
\text { enucleations }\end{array}$ & - & $21^{\mathrm{a}}$ & - & 14.1 \\
\hline $\begin{array}{l}\text { Median follow-up } \\
\text { (months) }\end{array}$ & 21 & $\begin{array}{l}28.5 \\
+/-44.4\end{array}$ & 44 & 35.4 \\
\hline $\begin{array}{l}\text { Globe salvage rate- } \\
\text { overall for intra- } \\
\text { ocular RB }(\%)\end{array}$ & 28.2 & - & - & - \\
\hline$\cdot \mathrm{A}$ & 100 & 100 & - & 100 \\
\hline - $\mathrm{B}+++$ & 94 & 100 & - & 100 \\
\hline$\cdot \mathrm{C}$ & 83 & 94.7 & - & 100 \\
\hline$\cdot \mathrm{D}$ & 54 & 17.1 & - & 29.4 \\
\hline$\cdot \mathrm{E}$ & 0 & 0 & - & 0 \\
\hline $\begin{array}{l}\text { Survival rates- } \\
\text { overall }(\%)\end{array}$ & $75.7^{\mathrm{b}}$ & $96.2^{\mathrm{c}}$ & 92 & 89.6 \\
\hline - Stage 3 & - & - & $71[23]$ & 55.5 \\
\hline - Stage 4 & - & - & $0[23]$ & \\
\hline \multicolumn{5}{|c|}{ Kaplan-Meier analysis } \\
\hline - 1 years & 83 & - & 94 & 93.1 \\
\hline - 3 years & 73 & - & 91 & 90.2 \\
\hline - 5 years & 68 & - & 90 & 89.2 \\
\hline
\end{tabular}

${ }^{*}$ Clinical features at presentation were based on individual eyes

${ }^{\#}$ Grouping and staging at presentation was not based on worst eye

${ }^{\mathrm{a}} \mathrm{A}$ total of 16 of 77 eyes undergoing primary enucleation with available histopathology reports had HRC

${ }^{\text {b }}$ Survival was 86.2 and $48.2 \%$ in the intra-ocular and extra-ocular group, respectively

${ }^{\mathrm{c}}$ Of the 347 patients who underwent treatment, at the last follow-up $3.7 \%$ children expired, $6.3 \%$ children were alive with local recurrence and $2.3 \%$ children had metastasis

et al. reported $55.5 \%$ overall survival rate in children with Stage 3 and 4 disease at presentation [21]. Kaliki et al. analyzed 80 patients with stage 3 or stage 4 disease at presentation and found that the survival rate were 71 and $0 \%$ in stage 3 and 4 , respectively [23].

Kaplan-Meier survival analysis showed 83-94\%, 73$91 \%$ and $68-90 \%$ overall survival at 1,3 and 5 , respectively in large case series [18-21]. Chawla et al. reported that on multivariate analysis of various prognostic factors, stage of the disease at presentation had a significant association with survival outcomes (extraocular vs intraocular, HR: 5.04, $p<0.001$ ) [18]. However, gender and laterality did not have any significant association with survival outcomes [18].

Singh et al. observed that $25.6 \%$ of all RB children seen in their center refused any form of treatment [20]. More importantly, of those undergoing treatment $43.5 \%$ ( 151 children) were defaulter of which $37.4 \%$ (130children) 
Table 4 Details of RB children who died during the course of treatment in India

\begin{tabular}{|c|c|c|c|}
\hline $\begin{array}{l}\text { Details of children } \\
\text { who died }\end{array}$ & $\begin{array}{l}\text { Chawla et al. } \\
\text { [18] }\end{array}$ & $\begin{array}{l}\text { Singh et al. } \\
{[20]^{*}}\end{array}$ & $\begin{array}{l}\text { Kaliki et al } \\
{[19]^{\#}}\end{array}$ \\
\hline $\begin{array}{l}\text { - Age at presentation } \\
\text { v/s overall }\end{array}$ & $35 / 29$ & & $44 / 32.6$ \\
\hline - Extra-ocular disease & 58.8 & $92.3 \%$ & 69 \\
\hline $\begin{array}{l}\text { - Advanced intra-ocular } \\
\text { disease }(D / E)\end{array}$ & & & 100 \\
\hline - Lag period & 12 & & \\
\hline - $\mathrm{H} / \mathrm{o}$ familiar RB & 8.9 & & \\
\hline
\end{tabular}

*Clinical features at presentation were based on individual eyes

${ }^{\#}$ Grouping and staging at presentation was not based on worst eye

were subsequently lost to follow-up [20]. Singh et al. reported an overall enucleation acceptation rate of $79.7 \%$ [20]. Chawla et al. reported that of $10 \% \mathrm{RB}$ children that were lost to follow-up, all (100\%) of them had advanced disease (Intra-ocular Group D/E \& Extra-ocular RB) [18]. These figures are alarming.

Table 4 shows details of RB children who died during the course of treatment. Chawla et al. and Kaliki et al. observed that the mean age of these children at presentation was 35 and 44 months vs. 29 and 32.6 months of the overall group, respectively [18, 19]. Most of these patients had advanced disease at presentation: $58.8-92.3 \%$ children had extra-ocular disease [18-20]. More importantly, $8.9 \%$ these children had a family historyr RB [18].

\section{Management of Orbital Retinoblastoma in India}

Contrast Magnetic resonance imaging (MRI) is the imaging modality of choice for orbital retinoblastoma to access the optic nerve and orbital extension and detect pineal tumor (trilateral retinoblastoma). Systemic evaluation and metastatic work up, including a detailed physical examination, which includes orbital examination and regional lymph node examination, complete haemogram, chest X-ray, ultrasonography of the abdomen, bone marrow biopsy, and cerebrospinal fluid cytology, are necessary to stage the disease. Whole body bone scans using Technetium-99 and Flourine-18 flourodeoxyglucose positron emission tomography (PET CT) scans are also useful for early detection of subclinical systemic metastasis [24, 25]. If regional lymph nodes are enlarged, a fine needle aspiration biopsy should be done to look for malignant cells.

In the past, orbital exenteration was used to treat patients with overt orbital disease. There is now evidence to show that a multi-modal approach comprising of neo-adjuvant chemotherapy, enucleation surgery, EBRT, and adjuvant chemotherapy is effective in cases with orbital and optic nerve spread, thus obviating the need for exenteration and better survival [26-29]. This approach consists of 3-6 cycles of high-dose systemic chemotherapy that induces tumor regression and makes the eye amenable to enucleation. More effective tumor control and a better safety profile was observed with VEC protocol as compared a 5 drug protocol consisting of carboplatin and etoposide, alternating with cyclophosphamide, idarubicin and vincristine [30]. Enucleation surgery is then followed by external beam radiotherapy 40-50c Gy given in fractionated doses to the orbit. High dose chemotherapy is continued for 12 cycles under close follow-up with a view to eradicate microscopic residual disease and prevent distant metastasis. CNS relapse was the most common cause of death in both groups [30].

Chawla et al. in a sub-group analysis of children with orbital $\mathrm{RB}$ at presentation at their center found that at last follow-up 39.2, 9 and $51.8 \%$ children were alive with no recurrence/metastasis, alive with metastasis and expired, respectively [18]. Metastasis to the CNS was noted in $15.7 \%$ and carried a poor prognosis [18]. Second malignant neoplasms were another major concern for survival with osteosarcoma being the commonest secondary malignancy. None of the cases was treated with orbital exenteration in this study [18].

\section{Retinoblastoma in Thailand}

The current population of Thailand is $\sim 69$ million (United Nations estimates). According to the nation-wide multicenter population-base prospective study of the incidence and survival rate of childhood cancer from Thai Pediatric Oncology Group (ThaiPOG), retinoblastoma is the 7th most common childhood cancer with the incidence of 3.1 per million population with overall survival probability at 5 years of $73 \%$ [31].

There are seven centers that provide treatment for retinoblastoma in Thailand, 4 in Bangkok (capital city) and 3 in each part of Thailand, north, northeast, and south. The survival rate of retinoblastoma in Thailand varies among each center and region of the country. Previous report from 3 cancer centers in north, northeastern and south Thailand during 1990 and 2009, which included 75 retinoblastoma patients, showed the survival rate of 40,50 and $75 \%$, respectively [32]. The survival rate of retinoblastoma patients from a single institute in Bangkok, which included 90 retinoblastoma patients during 1997 to 2006, showed the survival rate of $85 \%$ [33]. The overall survival rate of retinoblastoma patient from recent study in our center during 2007 to 2017 was 93\% (Rojanaporn, personal communication).

\section{Retinoblastoma in our center}

Ramathibodi Hospital is a university hospital of the Faculty of Medicine Ramathibodi Hospital, Mahidol University, located in Bangkok, the capital city of Thailand. Our center 
is currently the only center in Thailand and South East Asia region that has all the treatment modalities for retinoblastoma including systemic chemotherapy, intra-arterial chemotherapy (IAC), subtenon chemotherapy, intravitreal chemotherapy, cryotherapy, transpupillary thermotherapy (TTT), external beam radiotherapy (EBRT), and plaque brachytherapy with Ruthenium-106 (Ru-106).

\section{Treatment of retinoblastoma}

Treatment strategies were selected based on the disease stage, laterality, tumor location, visual prognosis, and input from the patient's family. EUA was performed during the course of treatment to evaluate treatment response.

Primary enucleation was recommended in unilateral advanced ICRB group D, or ICRB group E. However, in Thailand, where samsara is a common Buddhist belief, enucleation is assumed to affect one's well-being in the next life, making the procedure highly stigmatized. In cases that the parents strongly denied enucleation, we had to offer IAC or CRD, knowing that the chance of globe salvage is very poor. In this group of patients, enucleation after the failure of previous treatment would be more acceptable to the parents.

\section{Extraocular retinoblastoma}

Patients with extraocular tumors were given 3-6 cycles of high-dose chemotherapy, followed by enucleation or exenteration, external beam radiation therapy (EBRT), and adjuvant chemotherapy for 12 cycles, as previously described [28, 29].

\section{Our 10-year results}

There were 92 eyes of 61 retinoblastoma patients who were treated in our center during 2007 to 2017. The median age at diagnosis was 8 months (range, 1-48 months). Twentynine patients (47.5\%) were male. Thirty patients (49\%) had unilateral retinoblastoma. Two patients had familial retinoblastoma (3.3\%). The most common presenting symptoms were leukocoria (72\%) and strabismus (12\%). According to IRSS classification, 45 eyes (49\%) were IRSS stage 0, 44 eyes (48\%) were IRSS stage I, and 3 eyes (3\%) were IRSS stage III. Most of our patients $(76 \%)$ presented with advanced retinoblastoma. Of 92 eyes, 38 eyes $(41 \%)$ had ICRB group E, 25 eyes had ICRB group D (27\%), and 7 eyes $(8 \%)$ had extraocular retinoblastoma at presentation. Of 85 eyes with intraocular tumors, 67 eyes $(79 \%)$ received globe salvage therapy, including CRD alone in 36 eyes (42\%), CRD combined with other treatment modalities (IAC, IVT, Ru-106, or EBRT) in 25 eyes (29\%) and primary IAC in 6 eyes (7\%). Secondary enucleation was performed in 22 eyes (26\%) after demonstration of poor response to globe salvage therapy, while primary enucleation was performed in 18 eyes ( $21 \%$ ), which were eyes with advanced ICRB group D or ICRB group E. High-risk pathological features were found in the enucleated eyes of 8 patients with unilateral tumor, which all received postenucleation adjuvant chemotherapy.

At the median follow-up period of 26.8 months, the overall globe salvage rate of intraocular retinoblastoma was $53 \%$, with a globe salvage rate of $100 \%$ in ICRB Group A, B and C, $60 \%$ in Group D, and $21 \%$ in Group E. The overall survival rate was $93 \%$. Four patients passed away due to brain metastasis, febrile neutropenia, chemotherapy toxicity and secondary acute myeloid leukemia.

\section{Genetic testing}

Genetic testing was done in 52 patients (Rojanaporn, personal communication). We screened $R B 1$ mutations in our patients by using direct sequencing in combination with Multiplex Ligation-dependent Probe Amplification (MLPA). Of 52 patients, 27 patients $(52 \%)$ had unilateral retinoblastoma, and 25 patients $(48 \%)$ had bilateral retinoblastoma. Germline mutation was detected in $92 \%$ of bilateral retinoblastoma patients. Interestingly, we found high incidence of germline mutation in our unilateral retinoblastoma patients (33\%).

\section{Retinoblastoma in Singapore}

Singapore has had a unique experience regarding the incidence and management of retinoblastoma. Singapore's population has grown from 3.25 million in 2002 to the current population of about 6 million. Consequently, the annual incidence has risen from 1-3 patients to 2-5 patients per year. There are 2 main centers that manage retinoblastoma in Singapore. We herewith share the 15-year experience of the Retinoblastoma service, Dept. of Ophthalmology, National University Hospital. This dedicated team is comprised of Ophthalmic oncologists (Oculoplastic surgeon, Vitreoretinal surgeon, Pediatric Ophthalmologist), Pediatric oncologist, neurointerventional radiologist, ophthalmic pathologist and the Ocularists. Given Singapore's geographical location within Southeast Asia, comprising 11 nations, it is one of the centers of referral for challenging medical conditions. Consequently, retinoblastoma patients at various stages and for varied indications are referred to the National University Hospital [34]. Most patients were referred from Indonesia, Vietnam, Myanmar, Malaysia \& Brunei with occasional patient from Russia, Sri Lanka, India, Philippines and Papua New Guinea. Each of these nations has unique cultural, religious and economic background with highly variable basic medical and advanced 
Table 5 Retinoblastoma presentation at National University Hospital, Singapore

\begin{tabular}{ll}
\hline Age at presentation & $1-72$ months (mean 16.4 months) \\
Gender & Female 34 (56\%); Male 27 (44\%) \\
Laterality & Unilateral 36;Bilateral 25 \\
Nationality (in descending & Indonesia 29.5\%, Vietnam 21.3\%, Singapore 20\%, Brunei 9.8\%, Malaysia \\
order) & $6.6 \%$, Myanmar 4.9\%, Others(India, Sri Lanka, Papua new Guinea, Timor \\
& Leste \& Russia) \\
Grouping & Group A 1.16\%, Group B 8.2\%, Group C 26.3\%, Group D 39.3\%, Group E \\
& $24.7 \%$
\end{tabular}

Staging

Interventions prior to referral
Stage $083.6 \%$, Stage I $8.2 \%$, Stage II 1.6\%, Stage III 1.6\%, Stage IV $4.92 \%$

None $85 \%$, Enucleation of 1 eye $11.5 \%$, enucleation of both eyes $1.6 \%$, Intravitreal anti-VEGF injection $1.6 \%$.

${ }^{a}$ Excluding one 24 year old patient with advanced unilateral disease at presentation

surgical/interventional medical services. Since the development of a dedicated Retinoblastoma service, there had been significant changes in ophthalmologic and systemic assessment, and thus their staging and management with evolution from the historical Reese-Ellsworth classification to the currently practiced International (ICRB) Classification [35].

86 eyes of 61 patients were managed over a 15 -year period. A summary of the retinoblastoma patients is shown in Table 5.

Following a complete evaluation with appropriate Grouping and Staging, one or more of various interventions were performed. The most common immediate intervention was primary ocular enucleations, in 15 of 86 eyes (17.4\%). 3 of these 15 eyes (20\%) had histopathologic high-risk characteristics, warranting adjuvant chemotherapy. Eighteen patients who had been referred primarily for ocular enucleation underwent neoadjuvant chemotherapy. Chemotherapeutic regimens included VETOPEC (Vincristine, Etoposide and escalating doses of Cyclophosphamide) in three patients (prior to 2004) and VEC (Vincristine, Etoposide and Carboplatin) in 15 patients since. Of the 15 patients who received VEC regimen, 13 had bilateral retinoblastoma and two had advanced unilateral retinoblastoma. While all Group E eyes were unsalvageable, requiring enucleation, all contralateral eyes were salvaged, most with functional vision to lead independent and subsequently disease free lives.

Intraarterial chemotherapy for retinoblastoma was introduced at the National University Hospital, Singapore in 2014 and to date remains the only centre to offer it. Eight patients underwent intraarterial chemotherapy with an age range of 8-34 months. Spectrum of indications included parental choice to avoid systemic chemotherapy and enucleation $(n=4)$, only remaining eye with advanced disease having failed systemic chemotherapy $(n=2)$ and parental choice despite advanced Group E disease $(n=2)$. Spectrum of chemotherapeutic agents administered intraarterially included Melphalan, Topotecan and Carboplatin $(n=8)$.
The number of cycles administered ranged from 2-5 cycles. Four of eight eyes (50\%) were salvaged with intraarterial chemotherapy and consolidation therapy. Tumor Groups of these four salvaged eyes included Group $\mathrm{C}(n=2)$, Group $\mathrm{D}(n=1)$ and Group $\mathrm{E}(n=1)$. One child who had failed intraarterial catheterization at 12 months of age underwent bridging chemotherapy followed by subsequent successful IAC with globe salvage. Another child with bilateral advanced retinoblastoma, post-enucleation of one eye, underwent 5 cycles of IAC. While the posterior segment tumor completely resolved she developed anterior chamber seeds, was advised intracameral chemotherapy but defaulted follow-up. Except for two patients with failed cannulation there were no major complications encountered.

\section{Consolidation treatments}

With emerging trend of chemoreduction and increasing globe salvage, local consolidation treatment is being increasingly offered. These include transpupillary thermotherapy, transscleral cryotherapy and intravitreal chemotherapy. While exenterations, periocular chemotherapy and external beam radiotherapy are rarely performed these days, plaque brachytherapy, and intracameral chemotherapy are becoming more important with globe salvage treatment.

\section{Outcomes}

Principles of management of retinoblastoma include life salvage, followed by globe salvage and whenever possible vision salvage. When enucleation is performed, socket rehabilitation with a primary orbital implant and customized ocular prosthesis are just as important and becomes the $4^{\text {th }}$ goal of ideal management.

Life: 57 of 61 patients were alive and disease free at last follow-up post treatment. Spectrum of the four patients who succumbed to the disease all of whom were referred from the region are shown in Table 6 below. 
Table 6 Spectrum of presentation of 4 patient mortalities at National University Hospital, Singapore

Patient 13 -yr old with recurrent orbital disease and intracranial extension, with history of enucleation without histopathology control

Patient 2 3-yr old post-enucleation of one eye without histopathology control, presenting with metastasis and undiagnosed Group C tumor in the contralateral eye.

Patient 3 6-yr old who had undergone enucleation followed by external beam radiotherapy, referred for management of advanced contralateral disease with vitreous seeding, with incidental finding of an undiagnosed pinealoblastoma.

Patient 4 5-yr old diagnosed as 'Coat's disease' who had undergone multiple intravitreal anti-VEGF injections presenting with Stage IV metastastic disease.

Globe \& Vision salvage: All 13 patients (100\%) with bilateral retinoblastoma who underwent systemic chemoreduction with VEC protocol, had at least one globe salvaged, with functional vision sufficient to lead independent lives with low vision management where indicated. Four of eight eyes $(50 \%)$ who had undergone intraarterial chemotherapy had globe salvage, one of them with 20/40 vision.

Socket rehabilitation: All patients who underwent either a primary or a secondary ocular enucleation received primary orbital implantation with an alloplastic implant followed by customized ocular prosthesis [36]. Two of these eyes developed recurrent exposure of the orbital implant requiring secondary orbital implant exchange $(n=$ $1)$ or dermis fat graft placement $(n=2)$ with satisfactory outcome. Five of six patients who had undergone ocular enucleation prior to referral with second eye disease underwent secondary orbital implantation and customized ocular prosthesis.

\section{Discussion}

$\mathrm{RB}$ has transformed the molecular understanding about cancer pathogenesis [37]. Over the last century, retinoblastoma management has evolved from $>95 \%$ mortality to $>95 \%$ survival in developed nations [4]. Although no validated geographic or population preponderance has been noted, Asia-Pacific and Africa has the greatest disease burden owing to the large population with high birth rates [1]. Studies from different parts of the world have shown a wide variation in the clinical presentation and survival outcomes of children affected by retinoblastoma [7]. Analyzing retinoblastoma outcome data Canturk et al. found that survival correlates with human development index: 40\% (range 23-70) in lower-income countries (LICs), 77\% (range 60-92\%) in lower-middle income countries (MICs) and 79\% (range 54-93\%) in upper MICs [15]. In Great Britain for the study period of 1998-2002 the 5 year survival rates was $97 \%$ for unilateral $\mathrm{Rb}$ and $100 \%$ for bilateral $\mathrm{Rb}$ [8]. In US over the period of 30 years the 5 years reported actuarial survival rates increased from $92.3 \%$ (1975-1984), to $93.9 \%$ (1985-94) to $96.5 \%$ (1995-2004) [9]. Survival rates reported from India were 75.7 to $92 \%$ with a mean/median follow-up of 21-44 months [18-21]. Survival rates reported from less developed countries like Taiwan, Africa, Kenya, and Nepal are 64.41, 57.7 and $26.6 \%, 23.8 \%$, respectively [11-14].

There is little awareness about retinoblastoma in developing countries, even when a history of familial RB exists. This is exemplified by the fact that children with familial RB do not present early (24 months in familiar group vs. 29 months in overall group) and have significant mortality (constitute $8.9 \%$ children of those who died) [18]. Some of the reasons being, lower literacy rate, inadequate health-care facilities at the primary and secondary levels of health care, delays in the referral system, lack of facilities for genetic counselling and testing in resource limited setting. Leander et al. showed that $\mathrm{RB}$ awareness program linked to the national vaccination campaign in Honduras resulted in early presentation of $\mathrm{RB}$, the first inexpensive step towards improving survival [38].

Previous studies have found has no sex predilection in RB. In contrast, a male preponderance (nearly $60 \%$ ) was noted in all studies from India [18-21]. This is attributed to lack of attention to the female child in resource-limited setting owing to socio-economic and cultural reasons [39].

Singh et al. found that nearly $53.5 \%$ of the children were from rural areas and $13 \%$ children were from below poverty line (BPL) families [20]. Children from rural background and economically backward classes constitute a risk group. Children with a lower socioeconomic status were less likely to receive the recommended therapy and experience less favourable outcomes as compared to those with a higher socioeconomic level [40]. Issues include poor awareness, lack of trained primary health care workers, belief in indigenous system of medicine, accessibility to specialized treatment centers located in first-tier cities and financial constraints [16]. Most children would have advanced disease at presentation requiring complex, multimodal long duration of treatment resulting in poor compliance to treatment and loss of follow-up. Co-morbidities like lack of immunization, respiratory and gastrointestinal infections and malnutrition are more prevalent which further increase the morbidity and mortality. Chawla et al. reported that 13 of 146 children had died of disease unrelated to RB [18].

Singh et al. and Chawla et al. reported a mean delay in presentation was 3 and 8.3 months, respectively $[18,20]$. In 
contrast, shorter median lag period was reported in developed countries: England 8 weeks, United States 1.5 months for unilateral RB $[8,9]$. The difference in age of presentation among countries largely present the lag time to seek medical care, an indirect indicator of awareness about retinoblastoma and consequently advanced disease at presentation. Delay correlates with progression to advanced disease, which in turn is associated with higher mortality [5]. Chawla et al. reported that survival probability for children with lag period of less than 3 months was 89,78 and $68 \%$, respectively, at the end of 1 year, 2 years and 5 years, as compared with 76,67 and $59 \%$ for those with a lag period of more than 6 months [18].

Incidence of orbital RB in developed countries is low. Ellsworth et al. reported the incidence rate of orbital RB was $8.2,7.6$ and $6.3 \%$ between the years $1925-1959,1959$ 1974 and 1980-1986, respectively, further exemplifying the decreasing trend [41, 42]. In contrast, incidence rate as high as 36 and $40 \%$ have been reported from developing countries like Taiwan and Nepal, respectively [11, 43]. extraocular spread is associated with a 10-27 times higher risk of metastasis [44] and was predictive of low survival (hazard ratio 5.04, $P<0.001$ ) [45]..

Chawla et al. reported that of the total 434 children with intra-ocular RB, 60 children died [18]. Various causes were responsible such as the presence of microscopic residual disease and non-compliance to treatment [18]. Factors contributing to mortality are advanced intra-ocular disease (73-78\%) with high-risk HPE requiring complex multimodal treatment $[22,46]$. Defining a standard of care that is valid in both developed and developing countries alike is difficult [4]. In ideal conditions, treatment of RB requires a multi-disciplinary team consisting of ophthalmologists, pediatricians, oncologist, anesthetist, geneticist, pathologists, trained nurses under one roof [47]. Although cure at any cost is the goal in all developed countries today, governments in less developed countries are plagued with multiple high priority diseases like malaria, pneumonia and diarrhea more than $\mathrm{RB}$, a relatively rare disease. Compared to primary enucleation, globe salvage therapies require multiple cycles of chemotherapy with focal consolidations. Therefore, in terms of patient time, technological requirements cost and consequently poor compliance, enucleation may be preferred in less privileged countries.

Denial of treatment, poor compliance of treatment and low enucleation rates are issues unique to developing countries that needs to be addressed [16]. In a study by Chawla et al., lack of compliance towards treatment was noted in $25 \%$ cases that expired. Survival of patients whose families refused treatment even temporarily were significantly lower than those who did not refuse treatment [48]. Reasons for refusal included parental belief in alternative medicines, culture and social stigma. For example, fear of cosmetic disability hindering marital prospects post enucleation, especially of a female child, is common [16]. Moreover, refusal rate rises when health care specialists do not communicate effectively with the parents, meeting the psycho-social needs, explaining about retinoblastoma and its goals of treatment, management plan, excellent outcomes with good compliance and cosmetic rehabilitation post-enucleation [49]. Counselors, nurses, social workers, support groups may fill the void to gain the trust and overcome socio-cultural barrier in resource poor setting where health care system are over-burdened limiting the time a specialist can spend [49]. In developing nations care providers of traditional medicine are the first point of contact in most cases and preferred over the cosmetically disfiguring surgery of enucleation and monthly chemotherapy [16]. Because of the deep-rooted faith, appropriate and timely counselling by the care-providers of traditional medicine would be crucial in saving a life.

Concerted efforts towards overcoming socioeconomic and cultural factors will help in reducing the survival gap between the developed and developing countries. Possible steps include disease education and counselling, highly subsidized/free of cost treatment for low socioeconomic strata, raising funds through the government and nongovernmental organizations. Sensitization and training of ophthalmologists and paediatricians for early detection of retinoblastoma through a nationwide awareness campaign is required. The use of telemedicine for continuing education and consultation, identification of an apex center that could mentor other centers using a twining model and imparting specific training to health care providers can help to reduce delays in referrals [50].

In conclusion, our challenges in developing nations are not just technological, but also social. The true advances will not be made until the survival advances are extended to all the children in less developed countries in a meaningful and effective way. Education and universal screening alone plays an important role in addressing this factor.

We would also like to emphasize that this article is a view point of the authors given the published data and may not represent entire Asia.

Acknowledgements We acknowledge our colleauges at Sankara Netharalaya (Chennai), Dr. Rajendra Prasad Centre for Ophthalmic Sciences (AIIMS, New Delhi), National University Hospital (National University of Singapore, Singapore) and Ramathibodi Hospital (Mahidol University Faculty of Medicine, Bangkok, Thailand) for their support and guidance.

\section{Compliance with ethical standards}

Conflict of interest The authors declare that they have no conflict of interest. 


\section{References}

1. Kivelä T. The epidemiological challenge of the most frequent eye cancer: retinoblastoma, an issue of birth and death. $\mathrm{Br} \mathrm{J}$ Ophthalmol. 2009;93:1129-31.

2. Dimaras H, Kimani K, Dimba EA, Gronsdahl P, White A, Chan HS, et al. Retinoblastoma. Lancet. 2012;379:1436-46.

3. Kivelä T. 200 years of success initiated by James Wardrop's 1809 monograph on retinoblastoma. Actaophthalmologica. 2009;8:810-2.

4. Abramson DH. Retinoblastoma in the 20th century: past success and future challenges the Weisenfeld lecture. Invest Ophthalmol \& Vis Sci. 2005;46:2684-91.

5. Abramson DH, Beaverson K, Sangani P, Vora RA, Lee TC, Hochberg HM, et al. Screening for retinoblastoma: presenting signs as prognosticators of patient and ocular survival. Pediatrics. 2003;112:1248-55.

6. Dimaras H, Corson TW, Cobrinik D, White A, Zhao J, Munier FL, et al. Retinoblastoma. Nat Rev Dis Prim. 2015;1:15021.

7. Rodriguez-Galindo C, Wilson MW, Chantada G, Fu L, Qaddoumi I, Antoneli C, et al. Retinoblastoma: one world, one vision. Pediatrics. 2008;122:e763-70.

8. Broaddus E, Topham A, Singh AD. Survival with retinoblastoma in the USA: 1975-2004. Br J Ophthalmol. 2009;93:24-7.

9. MacCarthy A, Birch JM, Draper GJ, Hungerford JL, Kingston JE, Kroll ME, et al. Retinoblastoma: treatment and survival in Great Britain 1963 to 2002. Br J Ophthalmol. 2009;93:38-9.

10. MacCarthy A, Draper GJ, Steliarova-Foucher E, Kingston JE. Retinoblastoma incidence and survival in European children (1978-1997). Report from the Automated Childhood Cancer Information System project. Eur J Cancer. 2006;42: 2092-102.

11. Kao LY, Su WW, Lin YW. Retinoblastoma in Taiwan: survival and clinical characteristics 1978-2000. Jpn J Ophthalmol. 2002;46:577-80.

12. EN Gichigo, Kariuki-Wanyoike, Kimani MM, Nentwich K, Retinoblastoma MM. in Kenya: survival and prognostic factors. Ophthalmologe. 2015;112:255-60.

13. Goolam S, Kana H, Welsh N, Wainwright L, Poole J, Mayet I. A 20-Year Retrospective Review of Retinoblastoma at Two Tertiary Academic Hospitals in Johannesburg, South Africa. Ocul Oncol Pathol. 2018;4:170-5.

14. Prasad Sah K, Saiju R, Roy P, Kafle S Retinoblastoma: ten years experience at Kanti Children's Hospital. Journal of the Nepal Medical Association. 2013;52:576-9.

15. Canturk S, Qaddoumi I, Khetan V, Ma Z, Furmanchuk A, Antoneli CB, et al. Survival of retinoblastoma in less-developed countries impact of socioeconomic and health-related indicators. Br J Ophthalmol. 2010;94:1432-6.

16. Chawla B, Kumar K, Singh AD. Influence of socioeconomic and cultural factors on retinoblastoma management. Asia Pac J Oncol Nurs. 2017;4:187.

17. Usmanov RH, Kivelä T. Predicted trends in the incidence of retinoblastoma in the Asia-Pacific region. Asia-Pac J Ophthalmol. 2014;3:151-7.

18. Chawla B, Hasan F, Azad R, Seth R, Upadhyay AD, Pathy S, et al. Clinical presentation and survival of retinoblastoma in Indian children. Br J Ophthalmol. 2015;100:172-8.

19. Kaliki, S., Patel, A., Iram, S., Ramappa, G., Mohamed, A., \& Palkonda, V. A. R. (2017). RETINOBLASTOMA IN INDIA. Retina, 1. https://doi.org/10.1097/iae.0000000000001962

20. Singh U, Katoch D, Kaur S, Dogra MR, Bansal D, Kapoor R. Retinoblastoma: a sixteen-year review of the presentation, treatment, and outcome from a tertiary care institute in Northern India. Ocul Oncol Pathol. 2018;4:23-32.
21. Shah PK, Narendran V, Kalpana N. Outcomes of intra-and extraocular retinoblastomas from a single institute in South India. Ophthalmic Genet. 2015;36:248-50.

22. Kaliki S, Shields CL, Eagle JR, Iram S, Shields JA. High-risk intraocular retinoblastoma: comparison between Asian Indians and Americans from two major referral centers. Retina. 2017;38:2023-9.

23. Kaliki S, Patel A, Iram S, Palkonda VA. Clinical presentation and outcomes of stage III or stage IV retinoblastoma in 80 Asian Indian patients. J Pediatr Ophthalmol Strabismus. 2017;54:17784.

24. Kiratli PÖ, Kiratli H, Ercan MT. Visualization of orbital retinoblastoma with technetium-99m (V) dimercaptosuccinic acid. Ann Nucl Med. 1998;12:157-9.

25. Moll AC, Hoekstra OS, Imhof SM, Comans EF, Meeteren AS, van der Valk P, et al. Fluorine-18 fluorodeoxyglucose positron emission tomography (PET) to detect vital retinoblastoma in the eye: preliminary experience. Ophthalmic Genet. 2004;25:31-5.

26. Chantada G, Fandiño A, Casak S, Manzitti J, Raslawski E, Schvartzman E. Treatment of overt extraocular retinoblastoma. Med Pediatr Oncol. 2003;40:158-61.

27. Chantada GL, Guitter MR, Fandiño AC, Raslawski EC, de Davila MT, Vaiani E, et al. Treatment results in patients with retinoblastoma and invasion to the cut end of the optic nerve. Pediatr Blood Cancer. 2009;52:218-22.

28. Honavar SG, Manjandavida FP, Reddy VA. Orbital retinoblastoma: An update. Indian J Ophthalmol. 2017;65:435.

29. Ali MJ, Honavar SG, Reddy VA. Orbital retinoblastoma: Present status and future challenges-A review. Saudi J Ophthalmol. 2011;25:159-67.

30. Chawla B, Hasan F, Seth R, Pathy S, Pattebahadur R, Sharma S, et al. Multimodal therapy for stage III retinoblastoma (International Retinoblastoma Staging System): A prospective comparative study. Ophthalmology. 2016;123:1933-9.

31. Wiangnon S, Veerakul G, Nuchprayoon I, et al. Childhood cancer incidence and survival 2003-2005, Thailand: study from the Thai Pediatric Oncology Group. Asian Pac J Cancer Prev. 2011;12:2215-20.

32. Wongmas $\mathrm{P}$, Jetsrisuparb A, Komvilaisak $\mathrm{P}$, et al. Incidences, trends and long term outcomes of retinoblastoma in three cancer registries, Thailand. Asian Pac J Cancer Prev. 2015;16:6899-902.

33. Atchaneeyasakul LO, Wongsiwaroj C, Uiprasertkul M, Sanpakit K, Thephamongkhol K, Trinavarat A. Prognostic factors and treatment outcomes of retinoblastoma in pediatric patients: a single-institution study. Jpn J Ophthalmol. 2009;53:35-9.

34. Aung L, Chan YH, Yeoh EJ, Tan PL, Quah TC. Retinoblastoma: a recent experience at the National University Hospital, Singapore. Ann Acad Med Singap. 2009;38:693-8.

35. Chantada G, Doz F, Antoneli CBG, et al. A proposal for an International retinoblastoma staging system. Pediatr Blood Cancer. 2006;47:801-5.

36. Jeyabal P, Sundar G. Anophthalmic sockets in retinoblastoma: a single center experience. Asia Pac J Ophthalmol. 2018. https://doi. org/10.22608/APO.201892.

37. Knudson AG. Mutation and cancer: statistical study of retinoblastoma. Proc Natl Acad Sci. 1971;68:820-3.

38. Leander C, Fu LC, Pena A, Howard SC, Rodriguez-Galindo C, Wilimas JA, et al. Impact of an education program on late diagnosis of retinoblastoma in Honduras. Pediatr Blood Cancer. 2007;49:817-9.

39. Borooah VK. Gender bias among children in India in their diet and immunisation against disease. Soc Sci Med. 2004;58:171931.

40. Pillay-van Wyk V, Bradshaw D. Mortality and socioeconomic status: the vicious cycle between poverty and ill health. Lancet Glob Health. 2017;5:e851-2. 
41. Ellsworth RM. Orbital retinoblastoma. Trans Am Ophthalmol Soc. 1974;72:79.

42. Grabowski EF, Abramson DH. Intraocular and extraocular retinoblastoma. Hematology/Oncology. Clinics. 1987;1:721-35.

43. Badhu B, Sah SP, Thakur SK, Dulal S, Kumar S, Sood A, et al. Clinical presentation of retinoblastoma in Eastern Nepal. Clin Exp Ophthalmol. 2005;33:386-9.

44. Gündüz K, Müftüoglu O, Günalp I, Ünal E, Taçyıldız N. Metastatic retinoblastoma: clinical features, treatment, and prognosis. Ophthalmology. 2006;113:1558-66.

45. Chawla B, Hasan F, Azad R, Seth R, Upadhyay AD, Pathy S, et al. Clinical presentation and survival of retinoblastoma in Indian children. Br J Ophthalmol. 2015;100:172-6.

46. Biswas J, Das D, Krishnakumar S, Shanmugam MP. Histopathologic analysis of 232 eyes with retinoblastoma conducted in an Indian tertiary-care ophthalmic center. J Pediatr Ophthalmol Strabismus. 2003;40:265.

47. Elzomor H, Taha H, Nour R, Aleieldin A, Zaghloul MS, Qaddoumi I, et al. A multidisciplinary approach to improving the care and outcomes of patients with retinoblastoma at a pediatric cancer hospital in Egypt. Ophthalmic Genet. 2017;38:345-51.

48. Sitorus RS, Moll AC, Suhardjono S, Simangunsong LS, Riono P, Imhof $S$, et al. The effect of therapy refusal against medical advice in retinoblastoma patients in a setting where treatment delays are common. Ophthalmic Genet. 2009;30:31-6.

49. Olteanu C, Dimaras H. Enucleation refusal for retinoblastoma: a global study. Ophthalmic Genet. 2016;37:137-43.

50. Austoker J, Bankhead C, Forbes LJ, Atkins L, Martin F, Robb K, et al. Interventions to promote cancer awareness and early presentation: systematic review. Br J Cancer. 2009;101(S2):31. 